\title{
Circulating levels of high molecular weight (HMW) adiponectin and total adiponectin in relation to fat distribution, oxidative stress and inflammation in Asian Indians
}

\author{
K. Indulekha ${ }^{\mathrm{a}}$, J. Surendar ${ }^{\mathrm{a}}$, R.M. Anjana ${ }^{\mathrm{a}}$, K. Gokulakrishnan ${ }^{\mathrm{a}}$, M. Balasubramanyam ${ }^{\mathrm{a}}$, \\ V. Aravindhan ${ }^{\mathrm{b}}$ and V. Mohan ${ }^{\mathrm{a}, *}$ \\ a Madras Diabetes Research Foundation and Dr. Mohan's Diabetes Specialities Centre, WHO Collaborating \\ Centre for Non-Communicable Diseases Prevention and Control, International Diabetes Federation Centre for \\ Education, Gopalapuram, Chennai, India \\ ${ }^{\mathrm{b}}$ Laboratory of Molecular Immunology, Anna University K. B. Chandrashekar Research Centre, Chennai, India
}

\begin{abstract}
Aim: To look at the association of total and high molecular weight (HMW) adiponectin with markers of fat distribution, oxidative stress and inflammation in Asian Indians.

Methods: A total of 120 subjects were chosen randomly from Chennai Urban Rural Epidemiological Study. Fasting HMW adiponectin levels, TNF-alpha and oxidized LDL were measured using ELISA. High sensitivity C reactive protein (hsCRP) was measured by a high sensitive nephelometric assay. Lipid peroxidation was measured by Tbars assay and protein carbonyl content was assessed by DNPH assay. Visceral and subcutaneous fat areas were assessed by computed tomography (CT) scan.

Results: When stratified based on the tertiles of visceral fat, the levels of total ( $p=0.03$ )and HMW adiponectin $(p=0.007)$ were highest in the first tertile followed by tertiles 2 and 3 whereas in tertiles of subcutaneous fat, there was no such trend. With increasing tertiles of Tbars, the levels of total $(p=0.03)$ and HMW adiponectin decreased $(p=0.002)$. The levels of HMW $(p<0.001)$ but not total adiponectin was also found to decrease with increasing tertiles of Protein carbonyl content. The levels of Total $(p=0.02)$ and HMW adiponectin $(p=0.004)$ were highest in the first tertile of oxidized LDL followed by tertile 2 and tertile 3. With increasing tertiles of TNF-alpha total $(p=0.01)$ and HMW adiponectin $(p=0.004)$ was found to decrease. With increasing tertiles of hs-CRP, Total $(p=0.005)$ and HMWadiponectin $(p=0.007)$ was found to decrease.

Conclusion: Oxidative stress markers, visceral but not subcutaneous fat and inflammation are associated with total and HMW adiponectin levles in Asian Indians.
\end{abstract}

Keywords: Metabolic syndrome, obesity, type 2 diabetes, Asian Indians, adipocytokines

\section{Introduction}

Adiponectin is an insulin sensitizing, antiatherogenic and anti-inflammatory adipokine secreted by the adipose tissue [1]. Decreased levels of adiponectin are

*Corresponding author: V. Mohan, Madras Diabetes Research Foundation and Dr. Mohan's Diabetes Specialities Centre, WHO Collaborating Centre for Non-Communicable Diseases Prevention, Control and IDF Centre for Education 4, Conran Smith Road, Gopalapuram, Chennai, 600086, India. Tel.: +91 444396 8888; Fax: +91 44 2835 0935; E-mail: drmohans@diabetes.ind.in. shown to be associated with type 2 diabetes and obesity, particularly in visceral obesity, and also correlate inversely with insulin resistance [2,3].

Adiponectin is of three isoforms- a low molecular weight timer, a medium molecular weight 6 mer and a high molecular weight (HMW) 12-18 mer [4]. The HMW adiponectin has been shown to be the most biologically active form of the hormone [5]. Weight loss has been shown to specifically increase the HMW adiponectin form [6]. Moreover, thiozolidinedione mediated improvements in insulin sensitivity has 
been shown to be facilitated by the HMW adiponectin form [7].

Chronic hyperglycemia causes the increased production of reactive oxygen species (ROS) and the resulting oxidative stress in the visceral adipose tissue is known to be a key event in the pathogenesis of diabetes [8,9]. Earlier studies have elucidated the effect of fat distribution and oxidative stress on total adiponectin levels [10]; but data on HMW adiponectin are sparse and mounting evidence indicates that the defects in adiponectin oligomerization and consequent HMW isoform formation could be because of the redox status [11]. Hence this study was done to look at the association of total and HMW adiponectin with markers of fat distribution, oxidative stress and inflammation in Asian Indians who have increased susceptibility to type 2 diabetes and premature coronary artery disease.

\section{Research design and methods}

Study subjects were recruited from the Chennai Urban Rural Epidemiological Study (CURES), an ongoing epidemiological study conducted on a representative population (aged $\geqslant 20$ years) of Chennai (formerly Madras), the fourth largest city in India. The methodology of the study has been published elsewhere [12]. Briefly, in Phase 1 of the urban component of CURES, 26,001 individuals were recruited based on a systematic random-sampling technique; Details of the sampling are described on our website (http://www.drmohans diabetes.com/ under the link 'Publications'). In Phase 2 of CURES, all the known diabetic subjects in Phase 1 were invited to the centre for detailed studies on vascular complications. In Phase 3 every tenth subject in Phase 1 was invited for special studies.

For the study, a total of 120 study subjects were, randomly selected using computer generated numbers from Phase 3 of CURES. Of these 40 subjects had type 2 diabetes (T2DM). Institutional ethical committee approval of the Madras Diabetes Research Foundation was obtained and written informed consent was obtained from all study subjects.

\subsection{Anthropometric measurements}

Anthropometric measurements, including weight, height, and waist circumference, were obtained using standardized techniques. Height was measured with a tape to the nearest centimeter. Weight was measured with a traditional spring balance that was kept on a firm horizontal surface. Waist circumference was measured using a non-stretchable fiber measuring tape. The body mass index (BMI) was calculated as the weight in kilograms divided by the square of height in meters. Blood pressure was recorded in the right arm in the sitting position to the nearest $2 \mathrm{mmHg}$ with a mercury sphygmomanometer (Diamond Deluxe BP apparatus, Pune, India). Two readings were taken 5 minutes apart and the mean of the two was taken as the blood pressure. A questionnaire was administered to the study subjects to collect details like self-reported current and past smoking [12].

\subsection{Biochemical parameters}

Fasting plasma glucose (FPG) (glucose oxidaseperoxidase method), serum cholesterol (cholesterol oxidase-peroxidase-amidopyrine method), serum triglycerides (glycerol phosphate oxidase-peroxidase-amidopyrine method), highdensity lipoprotein cholesterol (HDL-C) (direct method-polyethylene glycolpretreated enzymes) and Creatinine (Jaffe's method) were measured using Hitachi-912 Autoanalyser (Hitachi, Mannheim, Germany). The intra- and interassay coefficient of variation for the biochemical assays ranged between $3.1 \%$ and $7.6 \%$. Low-density lipoprotein cholesterol (LDL-C) was calculated using the Friedewald formula. Glycosylated hemoglobin (HbA1c) was estimated by high pressure liquid chromatography using the Variant machine (Bio-Rad, Hercules, CA). The intra- and interassay coefficient of variation of $\mathrm{HbA} 1 \mathrm{c}$ was less than $10 \%$.

Microalbumin concentration was measured in a fasting urine sample using an immunoturbidometric assay (Hitachi 902 autoanalyser; Roche Diagnostics) as described earlier [12]. The mean inter- and intraassay coefficients of variation were $3.5 \%$ and $4.2 \%$, respectively. Microalbuminuria was diagnosed if the albumin excretion was between 30 and $299 \mu \mathrm{g} / \mathrm{mg}$ of creatinine.

Fasting adiponectin levels were measured using radioimmunoassay (catalogue no. HADP -61 HK, Linco Research, St Charles, Mo, USA). The intra-assay and the inte rassay coefficients of variation were $3.8 \%$ and $7.4 \%$, respectively, and the lower detection limit was $1 \mathrm{ng} / \mathrm{mL}$.

Fasting HMW adiponectin levels were measured using ELISA (Millipore USA). The intra-assay and the interassay coefficients of variation were $3.8 \%$ and $7.4 \%$, respectively, and the lower detection limit was $1 \mathrm{ng} / \mathrm{mL}$.

High sensitivity C reactive protein (hsCRP) was measured by a high sensitive nephelometric assay using 
Table 1

Clinical characteristics of the study subjects according to the tertiles of HMW adiponectin adjusted for age and gender

\begin{tabular}{llllr}
\hline Parameters & $\begin{array}{l}\text { Tertile } 1 \\
(n=40)\end{array}$ & $\begin{array}{l}\text { Tertile } 2 \\
(n=40)\end{array}$ & $\begin{array}{l}\text { Tertile } 3 \\
(n=40)\end{array}$ & $P$ value \\
\hline Age (Years) & $38 \pm 7$ & $43 \pm 9$ & $48 \pm 11$ & 0.048 \\
Gender [Male (n\%)] & 32 & 18 & 18 & 0.001 \\
BMI (kg/m ${ }^{2}$ ) & $24.8 \pm 3.2$ & $25.7 \pm 4.5$ & $24.8 \pm 4.3$ & 0.362 \\
Proportion of diabetics (\%) & 37.5 & 47.6 & 14.6 & 0.005 \\
Systolic blood pressue (mmHg) & $118.9 \pm 15.6$ & $120.6 \pm 18.8$ & $127.5 \pm 15.8$ & 0.598 \\
Diastolic blood pressure (mmHg) & $76.8 \pm 11.8$ & $76.5 \pm 12.2$ & $78.4 \pm 8.8$ & 0.923 \\
Waist circumference (cm) & $88.3 \pm 7.9$ & $90.2 \pm 12$ & $89.1 \pm 11.2$ & 0.442 \\
Fasting blood sugar (mg/dl) & $115.2 \pm 51.8$ & $113.3 \pm 41$ & $96.21 \pm 31.6$ & 0.062 \\
HbAlc (\%) & $6.8 \pm 2.2$ & $6.8 \pm 1.7$ & $6.1 \pm 1.5$ & 0.302 \\
Total cholesterol (mg/dl) & $192.1 \pm 32.1$ & $185.9 \pm 36.7$ & $185.8 \pm 33$ & 0.026 \\
Triglycerides (mg/dl) & $187.1 \pm 127.8$ & $131.5 \pm 75.6$ & $124.2 \pm 75.2$ & 0.205 \\
HDL cholesterol (mg/dl) & $36.9 \pm 8.5$ & $44 \pm 12.7$ & $45.3 \pm 8.6$ & 0.872 \\
LDL cholesterol (mg/dl) & $117.8 \pm 33$ & $115.6 \pm 33.1$ & $115.6 \pm 31$ & 0.107 \\
Total adiponectin & $4.4 \pm 2.9$ & $7.7 \pm 3.2$ & $9.8 \pm 5.0$ & $<0.001$ \\
Creatinine (mg/dl) & $0.87 \pm 0.2$ & $0.86 \pm 0.1$ & $0.89 \pm 0.2$ & 0.577 \\
Microalbumin (mg/dl) & $17.5 \pm 5.4$ & $26.1 \pm 7.2$ & $17.4 \pm 4.3$ & 0.476 \\
Smoking [smokers (n)] & 14 & 8 & 6 & 0.070 \\
Drugs & & & & \\
Oral hypoglycemic drugs (OHA) & 5 & 12 & 0 & \\
Insulin & 3 & 0 & 1 & \\
Insulin + OHA & 0 & & & \\
\hline
\end{tabular}

a monoclonal antibody to CRP coated on polysterene beads (Dade Behring, Marburg, Germany). The intraassay and the inter-assay coefficient of variation for hsCRP were $4.2 \%$ and $6.8 \%$ respectively and the lower detection limit was $0.17 \mathrm{mg} / \mathrm{L}$.

TNF- $\alpha$ concentration was measured by Enzyme linked immunosorbent assay (ELISA) [Biosource, Europe] and the intra and inter-assay co-efficient of variation ranged between $3.4 \%$ and $7.7 \%$.

Oxidized LDL was measured using commercially available sandwich enzyme-linked immunosorbent assay (Mercodia, Uppsala, Sweden). The intra- and interassay coefficient of variation for the assay ranged between $5.5 \%$ and $8.6 \%$.

\subsection{Lipid peroxidation}

Plasma levels of Malonodialdehyde (MDA), a marker of lipid peroxidation was measured by thiobarbituric acid reactive substances (TBARS) using a fluorescence methodology [13]. Briefly, $0.2 \mathrm{~mL}$ of plasma was mixed with $10 \%$ SDS, $20 \%$ acetic acid and $0.53 \%$ TBA and boiled at $100^{\circ} \mathrm{C}$ for $1 \mathrm{~h}$. Butanol:pyridine $(15: 1)$ was added, mixed and centrifuged at $3000 \mathrm{rpm}$ for $10 \mathrm{~min}$. The organic solvent was removed and read at excitation $535 \mathrm{~nm}$ and emission $552 \mathrm{~nm}$. Absolute MDA levels were calculated by regression parameters using different concentrations of the standard, 1,1', 3,3',-tetramethoxypropane. Inter- and intra-assay coefficients of variation of the above method were $5 \%$ and $10 \%$, respectively.

\subsection{Protein carbonyls}

Protein carbonyl content [PCC] was evaluated by the 2,4-dinitrophenylhydrazine (DNPH) assay [14]. Blanks were run with $2 \mathrm{M} \mathrm{HCl}$ alone instead of DNPH reagent. Protein carbonyl content was expressed as $\mathrm{nmol} / \mathrm{mg}$ protein, using a molar absorption coefficient of $22,000 \mathrm{M}-1 \mathrm{~cm}-1$. Protein concentration was determined using a standard curve with bovine serum albumin (BSA: 0.25-5.0 mg/mL) dissolved in guanidine hydrochloride and read at $280 \mathrm{~nm}$. The intra and inter-assay coefficients of variation were 2.2 and $2.8 \%$ respectively.

\subsection{CT scan procedure}

Subcutaneous and visceral fat were measured using a Helical CT scan (General Electric, Milwaukee, WI) as previously described [15]. The scans were done at $120 \mathrm{kV}, 200-250 \mathrm{mAs}$. Subjects were requested to lie in the supine position with their arms above their head and legs elevated with a cushion. A single scan $(10 \mathrm{~mm})$ of the abdomen was done at the level of L4-L5 vertebrae and analyzed for a cross-sectional area of adipose tissue, which was expressed in centimeters squared. Areas were calculated by multiplying the number of pixels of a given tissue type by the pixel number (pixel density). The external contour of the waist was determined using a threshold of $-160 \mathrm{HU}$ (Hounsfield Unit), and the external bone contours were derived at $-30 \mathrm{HU}$. The pa- 
Table 2

Linear regression analysis using HMW adiponectin as the dependent variable

\begin{tabular}{llc}
\hline Independent variables & \multicolumn{2}{c}{ Dependent variable: HMW adiponectin } \\
\cline { 2 - 3 } & \multicolumn{1}{c}{$\mathrm{B}(95 \%$ C. I) } & $P$ value \\
\hline $\begin{array}{l}\text { Tbars } \\
\text { Unadjusted }\end{array}$ & $0.081(0.032-0.129)$ & 0.001 \\
$\begin{array}{l}\text { Tbars } \\
\text { (adjusted for age, gender, BMI, smoking and Creatinine levels) }\end{array}$ & $0.054(0.037-0.121)$ & $<0.015$ \\
$\begin{array}{l}\text { PCC } \\
\text { (Unadjusted) }\end{array}$ & $0.377(0.207-0.547)$ & $<0.001$ \\
$\begin{array}{l}\text { PCC } \\
\text { (adjusted for age, gender, BMI, smoking and Creatinine levels) }\end{array}$ & $0.307(0.138-0.445)$ & $<0.001$ \\
$\begin{array}{l}\text { Oxidized LDL } \\
\text { (Unadjusted) }\end{array}$ & $0.461(0.200-0.722)$ & 0.001 \\
$\begin{array}{l}\text { Oxidized LDL } \\
\text { (adjusted for age, gender, BMI, smoking and Creatinine levels) }\end{array}$ & $0.441(0.202-0.664)$ & 0.001 \\
$\begin{array}{l}\text { Hs- CRP } \\
\text { (Unadjusted) }\end{array}$ & $0.129(0.030-0.229)$ & 0.012 \\
$\begin{array}{l}\text { Hs- CRP } \\
\text { (adjusted for age, gender, BMI, smoking and Creatinine levels) }\end{array}$ & $0.150(0.025-0.208)$ & 0.001 \\
$\begin{array}{l}\text { TNF-alpha } \\
\text { (Unadjusted) }\end{array}$ & $0.106(0.008-0.204)$ & 0.034 \\
$\begin{array}{l}\text { TNF-alpha } \\
\text { (adjusted for age, gender, BMI, smoking and Creatinine levels) }\end{array}$ & $0.045(0.006-0.186)$ & 0.037 \\
\hline
\end{tabular}

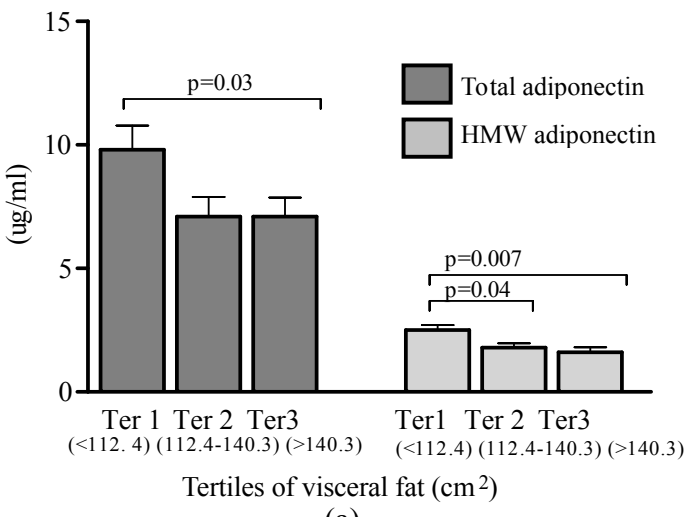

(a)

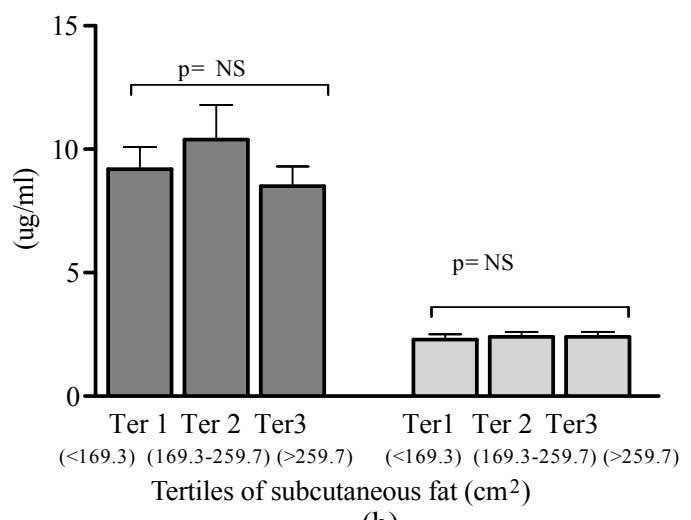

(b)

Fig. 1. (a): Levels of Total and HMW adiponectin in tertiles of visceral fat; (b): Levels of Total and HMW adiponectin in tertiles of subcutaneous fat.

rameters studied included visceral, subcutaneous, and total abdominal fat. Visceral fat was distinguished from subcutaneous abdominal fat by tracing along the fascial plane defining the internal abdominal wall.

\subsection{Definitions}

Diabetes was diagnosed based on criteria laid by the WHO Consultation Group report i.e. fasting plasma glucose $($ FPG $) \geqslant 7.0 \mathrm{mmol} / \mathrm{l}(126 \mathrm{mg} / \mathrm{dl})$ and/or $2 \mathrm{hr}$ post glucose value $\geqslant 11.1 \mathrm{mmol} / \mathrm{l}(200 \mathrm{mg} / \mathrm{dl})$ based on the past medical history, drug treatment for diabetes.

Insulin resistance was calculated using the homeostasis assessment model (HOMA-IR) using the for- mula: fasting insulin $(\mu \mathrm{U} / \mathrm{mL}) \times$ fasting glucose $(\mathrm{mmol} / \mathrm{L}) / 22.5$.

\subsection{Statistical analysis}

Data were expressed as mean \pm standard deviation (SD). The Student t-test or one-way analysis of variance (ANOVA) (with Tukey honestly significant difference [HSD]) as appropriate was used to compare groups for continuous variables. Linear regression analysis was done using HMW adiponectin as the dependent variable and various oxidative and inflammatory marker levels as independent variables. All analyses were done using Windows-based SPSS statistical package (Ver- 
sion 10.0 , Chicago). $P \leqslant 0.05$ was considered as significant.

\section{Results}

Table 1 shows the clinical and biochemical characteristics of the study subjects according to the tertiles of HMW adiponectin. Subjects in tertile 3 were older and also had significantly higher percentage of males. Hence all the other parameters were adjusted for age and gender. Total cholesterol $(p=0.026)$ were higher in subjects of Tertile 1 compared to those in tertile 2 and tertile 3 . The other parameters were not significantly different between the study subjects and all the subjects had normal renal function as shown by normal levels of microalbumin. The levels of total adiponectin were higher in tertile 3 compared to tertiles 2 and 1 ( $p<$ 0.001).

When stratified based on the tertiles of visceral fat, the levels of total $(9.8 \pm 0.9)(p=0.03)$ and HMW adiponectin $(2.5 \pm 0.2)(p=0.007)$ were highest in the first tertile followed by tertiles 2 and 3 whereas in tertiles of subcutaneous fat, there was no trend in the levels of total and HMW adiponectin as shown in Figs 1a and 1b. sex specific analysis showed that HMW adiponectin was found to be higher in case of women $(2.5 \pm 0.8$ vs $1.8 \pm 1 \mu \mathrm{g} / \mathrm{ml})(p=0.002)$. However when gender wise analysis was done, HMW adiponectin decreased significantly with increasing tertiles of visceral fat in both genders (Females: $2.6 \pm 0.9$ vs. $1.7 \pm 0.7$ vs. $1.2 \pm 0.9$; Males: $2.6 \pm 0.9$ vs. $2.3 \pm$ 0.9 vs. $1.8 \pm 0.8)$.

Figure 2(a) shows the levels of total and HMW adiponectin in tertiles of Tbars (Lipid peroxidation). With increasing tertiles of Tbars, the levels of total $(9 \pm$ $0.7)(p=0.03)$ and HMW adiponectin decreased (2.4 \pm $0.2)(p=0.002)$. The levels of HMW adiponectin, $(2.7 \pm 0.2)(p<0.001)$ but not total adiponectin was also found to decrease with increasing tertiles of Protein carbonyl content (PCC)/ protein peroxidation as shown in Fig. 2(b). Figure 2(c) shows that the levels of Total $(9.8 \pm 1.1)(p=0.02)$ and HMW adiponectin $(2.9 \pm 0.1)(p=0.004)$ were highest in the first tertile of oxidized LDL followed by tertiles 2 and 3 .

With increasing tertiles of inflammatory marker TNF-alpha, total $(8.2 \pm 0.5)(p=0.01)$ and HMW adiponectin $(2.5 \pm 0.1)(p=0.004)$ was found to decrease as shown in Fig. 3(a). With increasing tertiles of hs-CRP, total $(8.2 \pm 0.7)(p=0.005)$ and HMW adiponectin $(2.5 \pm 0.2)(p=0.007)$ was found to de-

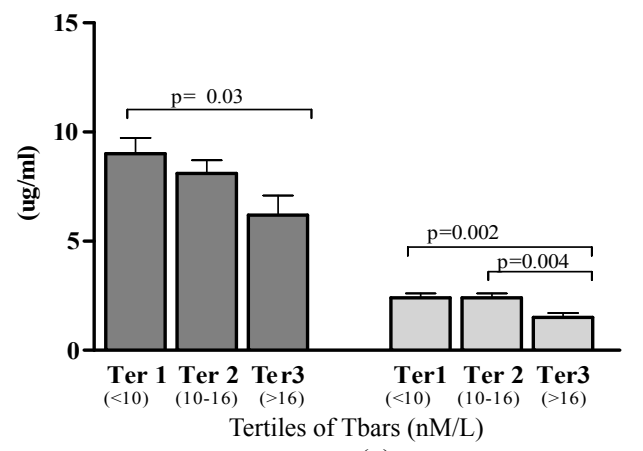

(a)

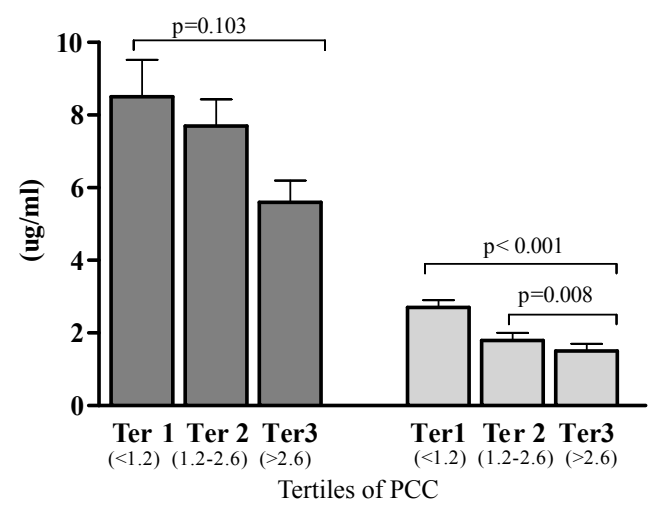

(b)

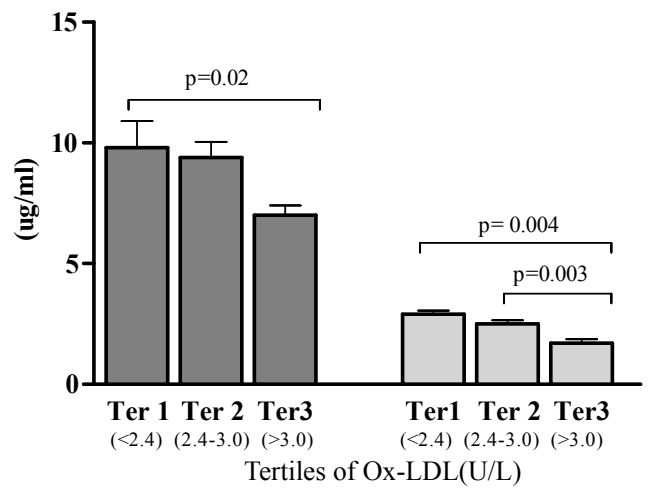

(c)

Fig. 2. (a): Levels of Total and HMW adiponectin in tertiles of Tbars; (b): Levels of Total and HMW adiponectin in tertiles of PCC; (c): Levels of Total and HMW adiponectin in tertiles of Oxidized LDL.

crease as shown in Fig. 3(a). Figure 4(a) shows the gender wise scatter diagram for HMW adiponectin. Figure 4(b) shows that total adiponectin showed a good correlation $(r=0.507, p<0.001)$ with HMW adiponectin.

Linear regression analysis showed that HMW adiponectin is negatively associated with Tbars $(B=$ $0.054 ; 95 \%$ C. I [0.037-0.121], $p<0.001), \operatorname{PCC}(B=$ $0.307 ; 95 \%$ C. I [0.138-0.445], $p<0.001)$, Oxidised 


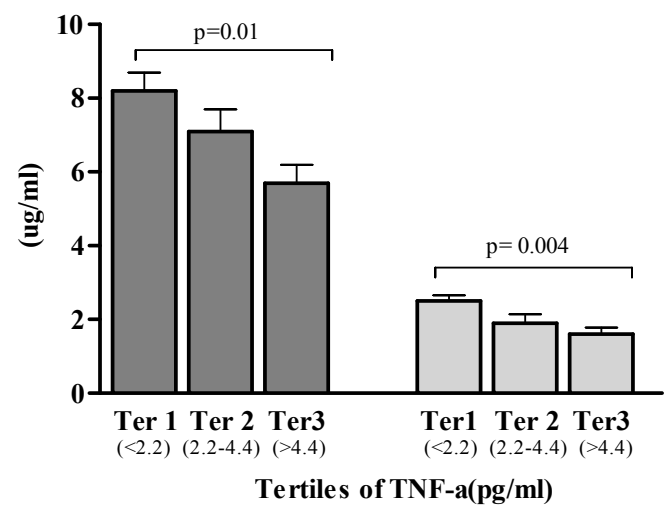

(a)

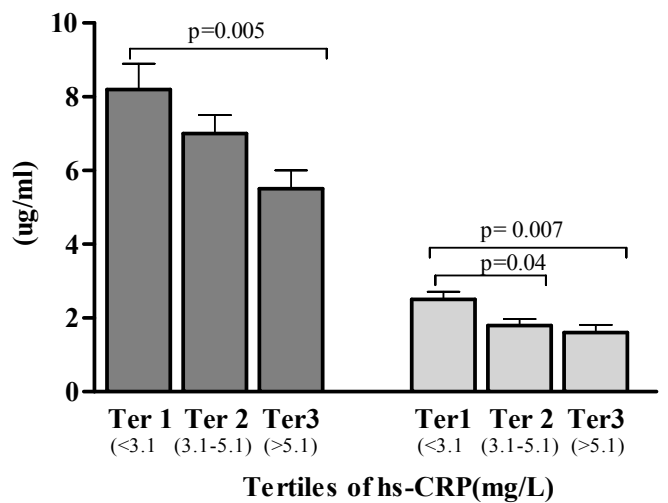

(b)

Fig. 3. (a): Levels of Total and HMW adiponectin in tertiles of TNF-alpha; (b): Levels of Total and HMW adiponectin in tertiles of hs-CRP.

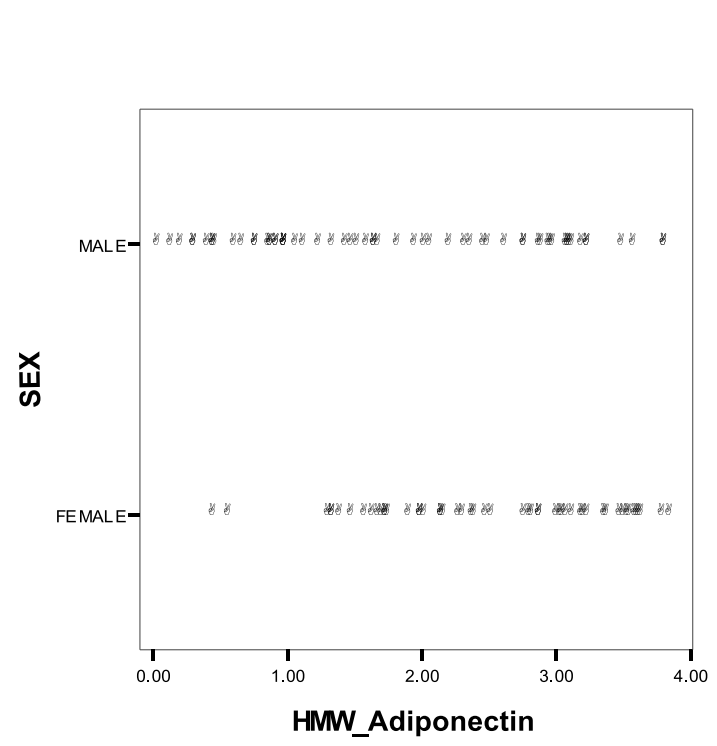

(a)

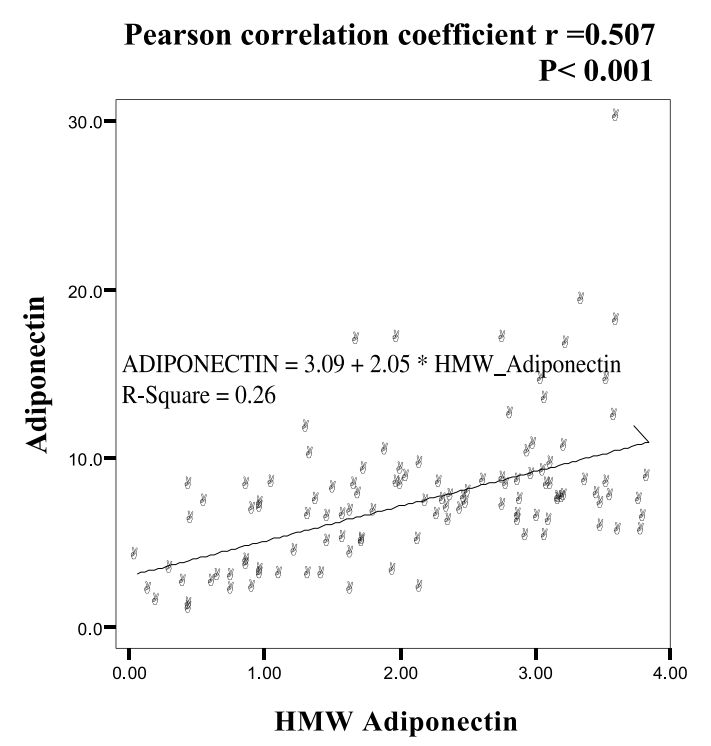

(b)

Fig. 4. (a): Gender wise scatter diagram for HMW adiponectin levels; (b): Correlation between total and HMW adiponectin.

$\operatorname{LDL}(B=0.441 ; 95 \%$ C. I $[0.202-0.664], p<0.001)$, hsCRP $(B=0.150 ; 95 \%$ C. I $[0.025-0.208], p=$ $0.014)$ and TNF alpha $(B=0.045 ; 95 \%$ C. I $[0.006-$ $0.186], p=0.037$ ) even after adjusting for age, gender, BMI, smoking and Creatinine.

\section{Discussion}

The major findings of the study are as follows: 1. With increasing levels of lipid and protein oxidation and oxidative stress markers, the levels of HMW adiponectin were decreased. 2 . With increasing levels of inflammatory markers like TNF-alpha and hs-CRP,
HMW adiponectin decreased. 3. HMW adiponectin was significantly associated with lipid and protein oxidation markers, oxidative stress markers and inflammatory markers even after adjusting for several factors like age, gender, BMI, smoking and creatine levels.

In the Asian Indian population there is only very little data assessing the metabolic significance of the multimeric forms of adiponectin. As each isoform of adiponectin activate different signaling pathways they exert differing effects on different tissues [16]. Hence it is important to study these isoforms in the context of diabetes related metabolic disturbances like fat accumulation, oxidative stress and inflammation.

Oxidative stress is induced by means of excessive reactive oxygen species production which could be a 
contributing factor for the pathophysiology of diabetes as hyperglycemia leads to the production of oxygen free radicals [17]. Diabetes is a pro-oxidant state characterized by increased LDL oxidation [18]. Our report shows that with decreasing levels of HMW adiponectin, oxidative stress markers like TBars, PCOs and Oxidised LDL were increased. Zhou et al. have shown in adiponectin knock out mice that the effects of oxidative stress on the respiratory chain are mediated by adiponectin [19]. In endothelial cells, adiponectin has been shown to suppress the production of reactive oxygen species, and protects cells from inflammation that results from exposure to high glucose levels or TNFalpha [20]. HMW adiponectin has been shown to inhibit the proliferation of hepatic stellate cells via the suppression of ROS generation [21]. Indeed, highly oxidizing conditions could also prove deleterious to the oligomerization of adiponectin itself [11]. Briggs et al. have shown that under highly oxidizing conditions, adiponectin trimers do not oligomerize properly [11]. Hence, under oxidizing conditions, the predominant oligomers were hexamers and trimers that oligomerized poorly into larger HMW species.

Distribution of adipose tissue has been shown to be an important determinant of inflammation [22]. Our findings are in agreement with the previous reports showing that with increase in visceral fat, HMW adiponectin levels decrease [23]. Earlier we have shown that total adiponectin decreases with increase in visceral fat and hence the association with total adiponectin could be due to the HMW form as shown in this study [10]. But this decrease in HMW adiponectin with increase in visceral fat was not reflected in case of subcutaneous fat. HMW levels did not show any trend with increasing tertiles of subcutaneous fat.

Increased secretion of TNF-alpha from the visceral fat could directly inhibit adiponectin secretion [24]. TNF-alpha levels increased with decreasing levels of HMW adiponectin and our findings agree with the results of Hajri et al. who showed that decline of adiponectin levels and alterations of isomer composition in plasma of obese subjects could be explained by increased TNF-alpha production [25]. Reduced HMW adiponectin and elevated hsCRP have been shown to be synergistically associated with the accumulation of metabolic disorders [26]. Hs-CRP could be elevated due to inflammation because the inhibitory effect of insulin on acute phase protein synthesis is inhibited in case of inflammation [27]. With all of the above parameters total adiponectin showed a similar trend to that of HMW adiponectin from which it can be speculat- ed that the differences in total adiponectin are mainly contributed by the differences in the HMW isoform.

In our study women showed higher levels of HMW adiponectin compared to men and this is consistent with other reports [28]. But in tertiles of visceral fat both men and women showed the same trend of decreasing adiponectin levels. The decreased levels found in men could be because of the inhibitory effect of testosterone on HMW adiponectin [28]. However, the limitations of the study are that the sample size is relatively small and the other multimeric forms of adiponectin are not looked into. Also, our study could not prove cause and effect relationship since it's a cross sectional study. In conclusion, we show that oxidative stress conditions, visceral but not subcutaneous fat and inflammation are associated with HMW adiponectin in Asian Indians.

\section{Conflict of interests}

None to declare.

\section{Acknowledgements}

We are grateful to the Chennai Willingdon corporate foundation, Chennai, for the financial support and the epidemiology team members for conducting the field studies. This is the 94th paper from CURES.

\section{References}

[1] Han SH, Sakuma I, Shin EK, Koh KK. Antiatherosclerotic and anti-insulin resistance effects of adiponectin: basic and clinical studies. Prog Cardiovasc Dis. 2009 Sep-Oct; 52(2): 126-40.

[2] Verkest KR, Rand JS, Fleeman LM, Morton JM, Richards AA, Rose FJ, Whitehead JP. Distinct adiponectin profiles might contribute to differences in susceptibility to type 2 diabetes in dogs and humans. Domest Anim Endocrinol. 2011 Aug; 41(2): 67-73.

[3] Kishida K, Kim KK, Funahashi T, Matsuzawa Y, Kang HC, Shimomura I. Relationships between circulating adiponectin levels and fat distribution in obese subjects. J Atheroscler Thromb. 2011 Jul 22; 18(7): 592-5.

[4] Kaser S, Tatarczyk T, Stadlmayr A, Ciardi C, Ress C, Tschoner A, Sandhofer A, Paulweber B, Ebenbichler CF, Patsch JR. Effect of obesity and insulin sensitivity on adiponectin isoform distribution. Eur J Clin Invest. 2008 Nov; 38(11): 827-34.

[5] Baumann M, von Eynatten M, Dan L, Richart T, Kouznetsova T, Heemann U, Staessen JA. Altered molecular weight forms of adiponectin in hypertension. J Clin Hypertens (Greenwich). 2009 Jan; 11(1): 11-6. 
[6] Magkos F, Mohammed BS, Mittendorfer B. Enhanced insulin sensitivity after acute exercise is not associated with changes in high-molecular weight adiponectin concentration in plasma. Eur J Endocrinol. 2010 Jan; 162(1): 61-6.

[7] Pajvani UB, Hawkins M, Combs TP, Rajala MW, Doebber T, Berger JP, Wagner JA, Wu M, Knopps A, Xiang AH, Utzschneider KM, Kahn SE, Olefsky JM, Buchanan TA, Scherer PE. Complex distribution, not absolute amount of adiponectin, correlates with thiazolidinedione-mediated improvement in insulin sensitivity. J Biol Chem. 2004 Mar 26; 279(13): 12152-62.

[8] Ceriello A, Motz E. Is oxidative stress the pathogenic mechanism underlying insulin resistance, diabetes, and cardiovascular disease? The common soil hypothesis revisited. Arterioscler Thromb Vasc Biol. 2004 May; 24(5): 816-23.

[9] Findeisen HM, Pearson KJ, Gizard F, Zhao Y, Qing H, Jones KL, Cohn D, Heywood EB, de Cabo R, Bruemmer D. Oxidative stress accumulates in adipose tissue during aging and inhibits adipogenesis. PLoS One. 2011 Apr 14; 6(4): e18532.

[10] Indulekha K, Anjana RM, Surendar J, Mohan V. Association of visceral and subcutaneous fat with glucose intolerance, insulin resistance, adipocytokines and inflammatory markers in Asian Indians (CURES-113). Clin Biochem. 2011 Mar; 44(4): 2817.

[11] Briggs DB, Giron RM, Malinowski PR, Nuñez M, Tsao TS. Role of redox environment on the oligomerization of higher molecular weight adiponectin. BMC Biochem. 2011 May 23; 12(1): 24.

[12] Deepa M, Pradeepa R, Rema M, et al. The Chennai Urban Rural Epidemiology Study (CURES) - study design and methodology (urban component) (CURES-1). J Assoc Physicians India 2003; 51: 863-70.

[13] Yagi K. A simple fluorometric assay for lipoperoxide in blood plasma. Biochem Med 1976; 15: 212-6.

[14] Levin RL, Garlan D, Oliver CN, Amici A, Clement I, Lenz AG. Determination of carbonyl content in oxidatively modified proteins. Methods Enzymol 1990; 186: 464-78.

[15] Lonn E, Yusuf S, Dzavik V, Doris C, Yi Q, Smith S, MooreCox A, Bosch J, Riley W, Teo K. SECURE Investigators: Effects of ramipril and vitamin $\mathrm{E}$ on atherosclerosis: the study to evaluate carotid ultrasound changes in patients treated with ramipril and vitamin E (SECURE). Circulation 2001; 103: 919-925.

[16] Neumeier M, Weigert J, Schäffler A, Wehrwein G, MüllerLadner U, Schölmerich J, Wrede C, Buechler C. Different effects of adiponectin isoforms in human monocytic cells. $\mathrm{J}$ Leukoc Biol. 2006 Apr; 79(4): 803-8.

[17] Baynes JW. Role of oxidative stress in development of complications in diabetes. Diabetes. 1991 Apr; 40(4): 405-12.

[18] Carru C, Pasciu V, Sotgia S, Zinellu A, Nicoli MC, Deiana L, Tadolini B, Sanna B, Masala B, Pintus G. The Oxidative State of LDL is the Major Determinant of Anti/Prooxidant Effect of Coffee on Cu Catalysed Peroxidation. Open Biochem J. 2011; 5: $1-8$.

[19] Zhou M, Xu A, Tam PK, Lam KS, Chan L, Hoo RL, Liu J, Chow KH, Wang Y. Mitochondrial dysfunction contributes to the increased vulnerabilities of adiponectin knockout mice to liver injury. Hepatology. 2008 ct; 48(4): 1087-96.

[20] Goldstein BJ, Scalia RG, Ma XL. Protective vascular and myocardial effects of adiponectin. Nat Clin Pract Cardiovasc Med. 2009 Jan; 6(1): 27-35.

[21] Adachi M, Brenner DA. High molecular weight adiponectin inhibits proliferation of hepatic stellate cells via activation of adenosine monophosphate-activated protein kinase. Hepatology. 2008 Feb; 47(2): 677-85.

[22] Sam S, Haffner S, Davidson MH, D’Agostino RB Sr, Feinstein S, Kondos G, Perez A, Mazzone T. Relation of abdominal fat depots to systemic markers of inflammation in type 2 diabetes. Diabetes Care. 2009 May; 32(5): 932-7.

[23] Ohashi N, Ito C, Fujikawa R, Yamamoto H, Kihara Y, Kohno $\mathrm{N}$. The impact of visceral adipose tissue and high-molecular weight adiponectin on cardio-ankle vascular index in asymptomatic Japanese subjects. Metabolism. 2009 Jul; 58(7): 10239.

[24] Fernández-Veledo S, Vila-Bedmar R, Nieto-Vazquez I, Lorenzo M. c-Jun N-terminal kinase $1 / 2$ activation by tumor necrosis factor-alpha induces insulin resistance in human visceral but not subcutaneous adipocytes: reversal by liver $\mathrm{X}$ receptor agonists. J Clin Endocrinol Metab. 2009; s94(9): 3583-93.

[25] Hajri T, Tao H, Wattacheril J, Marks-Shulman P, Abumrad NN. Regulation of adiponectin production by insulin: interactions with tumor necrosis factor- $\alpha$ and interleukin-6. Am J Physiol Endocrinol Metab. 2011 Feb; 300(2): E350-60.

[26] Tabara Y, Osawa H, Kawamoto R, Tachibana-Iimori R, Yamamoto M, sNakura J, Miki T, Makino H, Kohara K. Reduced high-molecular-weight adiponectin and elevated highsensitivity C-reactive protein are synergistic risk factors for metabolic syndrome in a large-scale middle-aged to elderly population: the Shimanami Health Promoting Program Study. J Clin Endocrinol Metab. 2008 Mar; 93(3): 715-22.

[27] Festa A, D’Agostino R Jr, Howard G, Mykkänen L, Tracy RP, Haffner SM. Chronic subclinical inflammation as part of the insulin resistance syndrome: the Insulin Resistance Atherosclerosis Study (IRAS). Circulation. 2000; 102(1): 427.

[28] Xu A, Chan KW, Hoo RL, Wang Y, Tan KC, Zhang J, Chen B, Lam MC, Tse C, Cooper GJ, Lam KS. Testosterone selectively reduces the high molecular weight form of adiponectin by inhibiting its secretion from adipocytes. J Biol Chem. 2005 May 6; 280(18): 18073-80. 


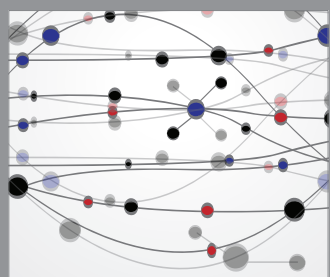

The Scientific World Journal
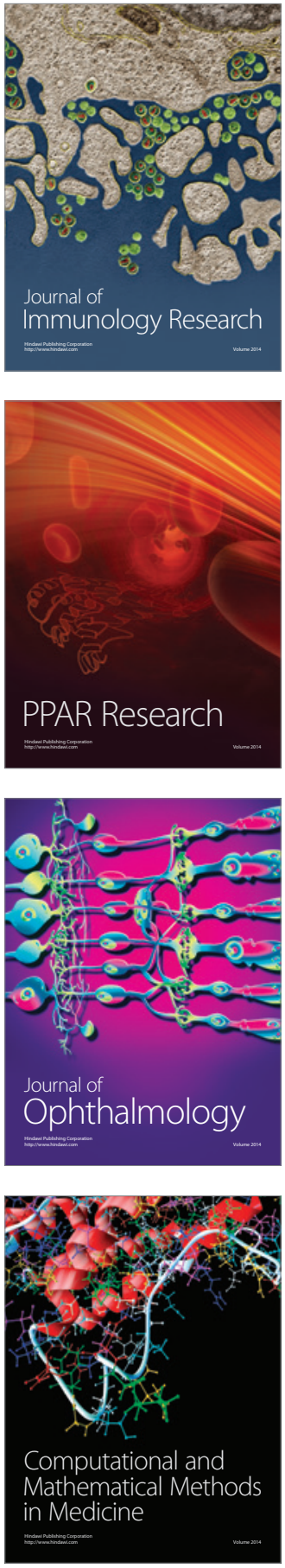

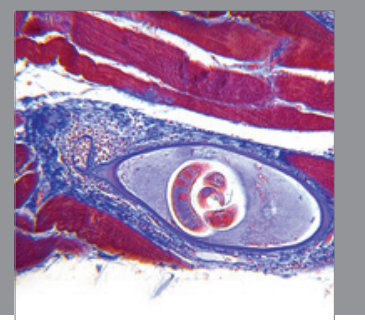

Gastroenterology

Research and Practice
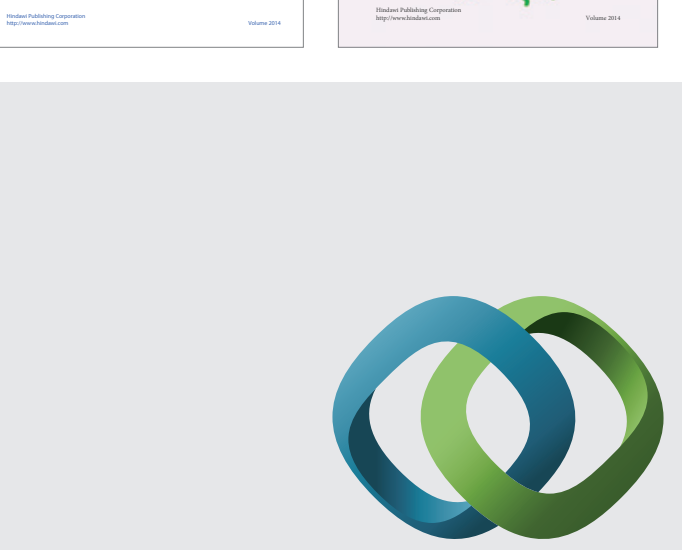

\section{Hindawi}

Submit your manuscripts at

http://www.hindawi.com
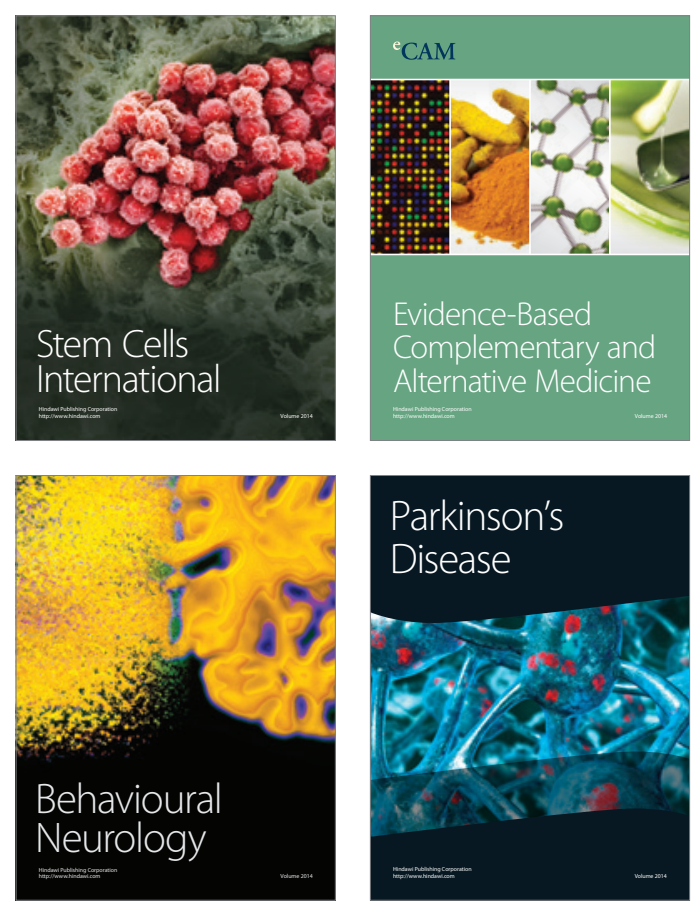

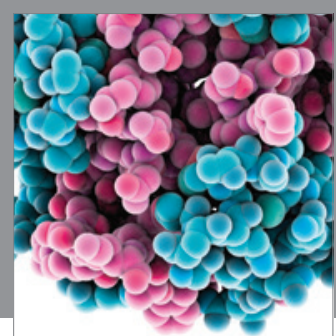

Journal of
Diabetes Research

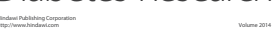

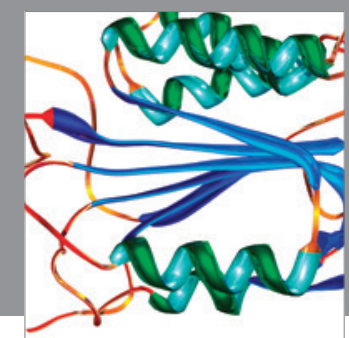

Disease Markers
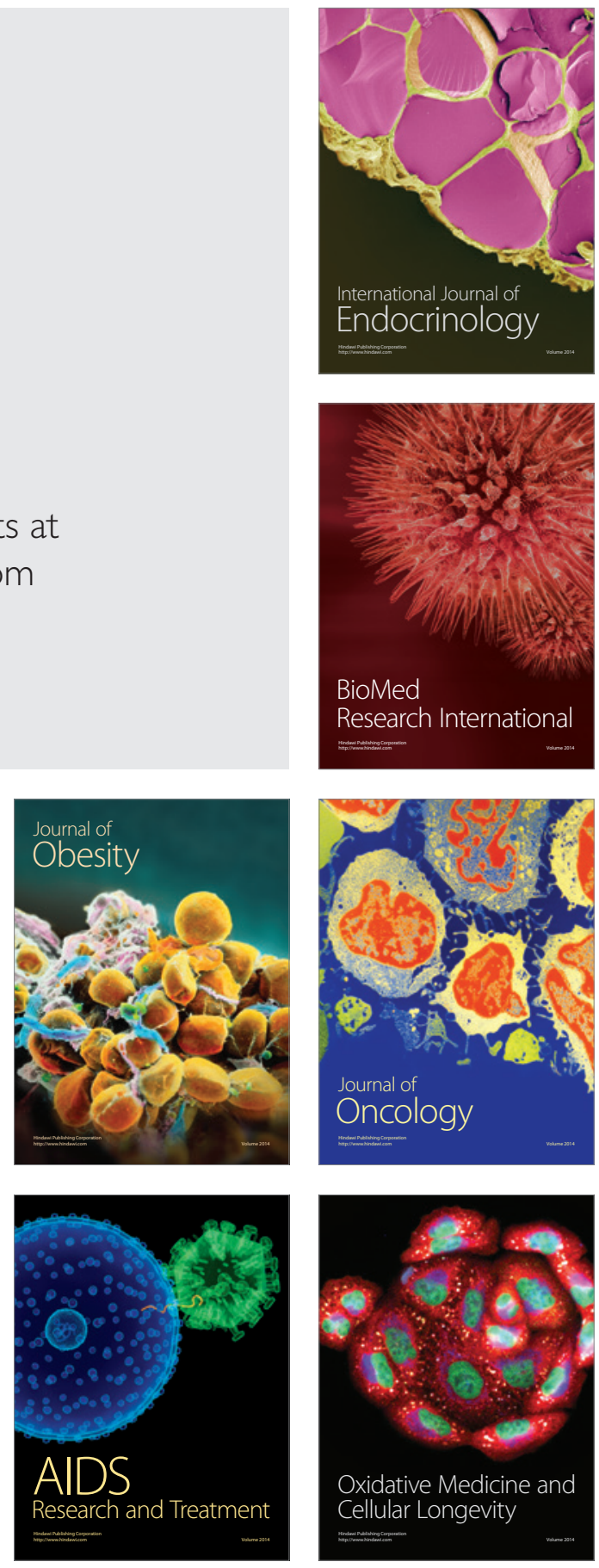